\title{
Factors Associated with Quality of Care Among Dependent Older Persons in the Community
}

\section{Kamonrat Kittipimpanon Supichaya Wangpitipanit (D)}

Department of Community Health Nursing, Ramathibodi School of Nursing, Faculty of Medicine, Ramathibodi Hospital, Mahidol University, Bangkok, Thailand
Correspondence: Supichaya

Wangpitipanit

Department of Community Health

Nursing, Ramathibodi School of Nursing, Faculty of Medicine, Ramathibodi

Hospital, Mahidol University, 270 Rama VI

Road, Thung Phaya Thai, Ratchathewi,

Bangkok, 10400, Thailand

Tel +66 819628729

Email supichaya.wan@mahidol.ac.th
Introduction: Dependent older persons who are limited in their daily activities affect physical, mental, social ability needs help in the family and the community caregiving.

Objective: The study aimed to analyze the relationship between caregivers' characteristics and health conditions, social support, the burden of care, and the quality of respect for the dependent older persons.

Methods: The descriptive study design applies in using a Donabedian framework, including structure, process, and outcome with House's social support. The sample consists of 102 family caregivers currently caring older people with dependency in Bangkok, Thailand. Data were collected through questionnaires, semi-structured interviews, and care quality assessments through tested content validity from 3 health experts, which received a score of 0.97 . Descriptive statistics and correlation coefficients were used to analyze the information and tested using Spearman's rank correlation; acceptable criteria were obtained before collecting the actual data.

Results: The results showed that they were statistically significantly related to social support and quality of care. When considering each aspect, social support was associated with the quality of physical and psychological care. Resource social support was to relate the quality of medical and financial aspects. Social support of acceptance and appreciation is associated with quality, environmental, physical, psychological, human rights, and economic elements; information social support was significantly related to information supervision quality.

Discussion: This study found that personal factors in age and comorbidity affect the burden of care in family caregivers. In addition, good social support will affect the quality of respect for the dependent older persons in psychological, medical, human rights, and financial dimensions. In particular, the appraisal support, incredible care, attentiveness, and dedication to care will result in a good quality of care in all areas except the quality of physical dimensions.

Keywords: dependent older persons, social support, quality of care, family caregiver, community

\section{Introduction}

Worldwide, in the population facing the aging society problems, there were around $20 \%$ of older persons who were unable to perform activities in daily life according to one's competencies and have to experience the deterioration in the physical, mental, emotional, social, economical aspects, leading to the development of dependence and the need of caregiving. ${ }^{1,2}$ The population aged in Asia, over sixty percent of the world's older persons, will be single and couple households increase. Care service provision needs to cover not only independent living but also long-term care in the field of service public. ${ }^{3}$ Thailand is in an utterly aging society, 
where it is found that around 18.10 percentage of them are dependent or overall approximately two hundred thousand people. $^{2}$ They have families that play most crucial role in coping with caregiving problems. In the past ten years, 89.2 percentage of the family members were family caregivers such as spouses, children, siblings, relatives. They found that older people who live alone in the household tended to increase. ${ }^{4}$ It is necessary to develop a long-term care system for giving a good quality of life. After that, they need care from the official replacement service, government, public health-care system, formal and informal caregivers by family, neighbors, or community volunteers. If they were not getting reasonable care, it decreases the quality of life or disability and subsequent death. ${ }^{1-4}$

Literature reviews found that the factors related to dependence for older persons have both family and social factors such as personal factor health condition, ability to perform daily activities, family relationship and the environment in which they can live. Besides, the increasing number of older persons tends to increase the caregiving burden and increse the costs. This is around $2.8 \%$ of GDP, expected to amount to two hundred and twenty billion baht in the year 2022.,5 Bangkok metropolis, the capital, is a large urban community of Thailand. A city comprehensive plan system provides valuable resources, facilitating transportation, logistics. It appears to use a long-term care system provided by a multidisciplinary team, coordinating the relationship between the community and the service center by providing care plans, care managers, and caregivers to reduce caregiving costs. ${ }^{4}$

However, we found that caregiving situation for the dependence of older persons in the rural communities is close to each other, both from family and good relationships with their neighbors. People in the community who help depend on each other and there is constant active supervision of a multidisciplinary team. ${ }^{5,6}$ It is very different from Bangkok health services; we found a moderate quality of life, environment, and health. Besides, Bangkok is a large community with an urban plan, slum community, and high-rise community. We found that the complexity of social and environmental problems was relatively high. ${ }^{6-8}$ The review of the relevant literature cannot find factors related to the quality of care for older persons with dependency in an urban area with lifestyles in different contexts. Therefore, it is a source of interest to the study. These situations inevitably affect the quality of care for the dependent persons. The researchers' reason is to investigate factors associated with quality of care among dependent older persons in the community. The study aimed to analyze the relationship between caregivers' characteristics and health conditions, social support, the burden of care, and the quality of respect for the dependent older persons.

\section{Materials and Methods}

This study received ethical approval from the Human Research Ethics Committee, Faculty of Medicine Ramathibodi Hospital, Mahidol University (number COA. MURA2020/1991); all participants gave written informed consent, in accordance with the Declaration of Helsinki.

According to selection criteria, it was primary caregivers and dependent older persons by purposive sampling. There were 102 families from five public health centers in Dusit district, Bang Sue district, and Phayathai district. It was applied to both the Donabedian concept (structure, process, and outcome $)^{9}$ and the House's social support ${ }^{11}$ of four domains: informational, instrumental, appraisal and emotional support to assess the quality of care of six dimensions: environmental, physical, medical, psychological, human rights, used as a conceptual framework. ${ }^{10}$

Data collections have four instruments that used later criteria which included the dependent older persons from the Barthel ADL index instrument: (1) Personal information interview form for older persons and their caregivers, (2) social support questionnaire which adapted Thai version from the House has 20 questions on a 4-point scale; answering response alternatives were from $0=$ disagree none to $3=$ strongly agree, (3) The Burden Interview for caregivers ${ }^{12}$ has 22 questions on a 5-point scale; answering response alternatives were from $0=$ none to $4=$ mostly done, and (4) the QUALCARE scale which was translated into Thai version from the the work by Philips et $\mathrm{al}^{11}$ that has a total of 30 questions on a 5-point scale; answering response alternatives were from $1=$ excellent to $5=$ poor. Three experts in the fields of gerontology, community nurse, and instructor validated the instruments and contents. The content validity index was 0.97. After gathering suggestions from experts, they were taken into attention for revising and the pre-test reliability with 15 family caregivers who were similar to the sample. Cronbach's alpha demonstrated acceptable reliability of 0.74 to 0.97 for the main study. A face-to-face interview was conducted, which took approximately 30-45 minutes. Each participant's scores were collected from the dependent older persons and their caregivers for self-assessment by a response method. By using PASW 
Statistics (version 18.0), analysis of the data processing was performed. Descriptive data showed averages, standard deviation, percentages, and Spearman's rank correlation were used to find the relationship between personal factors, comorbidity, income, social support towards burden, and quality of care.

\section{Results}

There were 102 families from five public health centers by purposive sampling. The results showed that the age of dependent older persons ranges from 61 to 100 years; the average age is $79.61 \pm 8.64$. Most of them were female (76.5\%), marital status widowed (58.8\%), Buddhism $(96.1 \%)$, stay together with your family $(52.9 \%)$. The most common diseases are hypertension (75.5\%), hyperlipidemia (44.1\%), and cerebrovascular disease (38.2\%), respectively. The caregivers giving time to caretaker-dependent older persons were between 20 and 88 years old, with an average age of $55.32 \pm 13.15$, and found aged $\geq 80$ years $(4.9 \%)$. Most of them were female (78.4\%), marital status couples (49.0\%), Buddhism (95.1\%), sufficient income (78.4\%). The most common diseases are hypertension (40.2\%), hyperlipidemia (32.4\%), and diabetes milieus (19.6\%), respectively. Most of them do not have a caregiving burden (78.4\%). Quality of care for the dependent older persons was reasonably poor (55.9\%), with an average of 69.16 hours of care per month; more details are shown in Table 1.

Moreover, the results show a significant positive correlation between social support for the caregiver's burden. We found that variables' age $(r=0.24 ; \mathrm{P}=0.014)$, comorbidity $(\mathrm{r}$ $=0.21 ; \mathrm{P}=0.038)$, and social support $(\mathrm{r}=0.23 ; \mathrm{P}=0.020)$ were statistically significant by analyzing Spearman's rank correlation method. The analysis results show that the information has a statistically significant relationship between social support and quality of care. When considering each aspect, emotional and instrumental social supports are associated with the quality of medical, psychological care, financial income dimensions. In each dimension, an appraisal of
Table I Social Support, Quality of Care, and Burden Scores

\begin{tabular}{|l|l|}
\hline Domain & Average \pm SD \\
\hline Social Support (0 = disagree to 3 = strongly & \\
agree) & \\
Emotional Support & $2.74 \pm 0.40$ \\
Instrumental Support & $2.59 \pm 0.49$ \\
Appraisal Support & $2.65 \pm 0.45$ \\
Information Support & $2.54 \pm 0.46$ \\
\hline QUALCARE Scales (I= excellent to 5 = poor) & \\
Environmental & $1.86 \pm 0.53$ \\
Physical & $2.01 \pm 0.74$ \\
Medical management & $1.76 \pm 0.57$ \\
Psychological & $1.86 \pm 0.60$ \\
Human rights & $1.84 \pm 0.61$ \\
Financial Aspect & $1.73 \pm 0.61$ \\
\hline Burden Scores (0-80 Points) & Percentage \\
No ( $\leq 20$ points) & 61.8 \\
Yes (>20 points) & 38.2 \\
\hline
\end{tabular}

social support related to the quality of care of the environment, medical, psychological care, human resource, financial income dimensions, and information support was associated with the quality of care of medical components shown in Table 2.

\section{Discussion}

This study finds a significant positive correlation between caregivers' characteristics and health conditions, social support, the burden of care, and the quality of respect for the dependent older persons. According to the Donabedian framework, the process was caregiving as a level of personal, family, and community care. Regarding outcome themes, there were quality of care, long-term care system, and application of information media benefits technology and digital. The results of this study were consistent findings of previous research that the age factor of older persons is related to care, and a third of caregivers felt a significant burden on their caregivers. Older persons

Table 2 Relationship Between Each Component of Social Support and QUALCARE

\begin{tabular}{|l|l|l|l|l|l|l|}
\hline Variables & \multicolumn{5}{|c|}{ QUALCARE } \\
\hline Social Support & Environment & Physical & Medical & Psycho & Human R. & Financial \\
\hline Emotional Support & 0.148 & 0.142 & $0.241^{*}$ & $0.215^{*}$ & 0.190 & $0.221^{*}$ \\
Instrumental Support & 0.142 & 0.149 & $0.276^{* *}$ & $0.276^{* *}$ & 0.131 & $0.276^{* *}$ \\
Appraisal Support & $0.213^{*}$ & 0.188 & $0.231^{*}$ & $0.256^{* *}$ & $0.308^{* *}$ & $0.289^{* *}$ \\
Information Support & -0.060 & 0.059 & $0.275^{* *}$ & 0.183 & 0.170 & 0.123 \\
\hline
\end{tabular}

Notes: ${ }^{*} p$-value $<0.05,{ }^{* *} p$-value $<0.01$. 
have many congenital diseases, more burden to manage, need help from caregivers a lot as well. ${ }^{13-15}$

Furthermore, we found that the social support factor is statistically significantly related to the quality of care in the medical and psychological dimensions. It was consistent with the research which found that the ability to perform daily activities of older persons with a dependency with daily activities such as bathing and dressing as $13.8 \%$, the need to move to places and in their homes as $38.2 \%$ and $15.9 \%$, respectively. In addition, $8.7 \%$ of drug use errors were to have incidence reported, and several studies show that the need for reinforcement is informative. Mental and emotional care, including medical care, continuous care, will affect satisfaction and result in good quality of care. ${ }^{16,17}$ In particular, assistance from family members significantly correlated with the burden on caregivers. In the same way, ethnic and cultural factors lead to differences in caregiver networks that can affect the quality of care. Consistent with the study of volunteer caregivers for other acute dementia patients, the impact and relationship between volunteers and family caregivers included a lack of sufficient time to provide care. There are environmental restrictions, unclear roles, and proper care to find if using the deployment and training resource package for volunteering contributes to increased emotional care, physical care, quality of care, and reduces the burden of caring for families and volunteers. ${ }^{18,19}$

These findings were congruent in terms of emotional, cognitive, usefulness, and core values that were statistically significantly related to medical, psychological, and financial care quality. This is consistent with research reporting that health-care providers, particularly primary care physicians, remain essential in identifying caregivers caring for dependent older people in the community, help to screen health problems and suffering of people at the community level. Family caregivers can consult the health-care provider to promptly help older persons with dependency, including creating satisfaction in the service. ${ }^{19,20}$ As for family caregivers, they found that the related factors included poor health and financial problems. There should be special attention and concern about the need and tribulations of the caregiver group. ${ }^{21}$ This study was consistent with the research by learning about health-care providers and having an excellent care process helping caregivers promote positive activities, especially leadership skills. By gaining exposure and experience to enhance organizational collaboration and communication in managing interdisciplinary client health issues, centralized coordination to manage and monitor patient care continues due to long-term care. ${ }^{22-24}$
Moreover, these findings were congruent with appraisal support which significantly related that the supportive environments also have an important influence on the development, and maintenance of healthy behaviors and enabling families were essential to them, despite losses in capacity in caregiving. ${ }^{25}$ In addition to managing a holistic health-care system, health professionals must strengthen the involvement of caregivers in the transition between care and health care. In addition, we should assess the targeted strategies for formal caregivers to continue cooperating, supporting, and empowering family members as informal caregivers. ${ }^{25-29}$ The study suggested gathering data for planning, operations, training, providing knowledge, and practicing care skills, establishing guidelines for the caregiving of the dependent older persons in the present scenario for health and social workers from related agencies.

\section{Conclusion and Recommendation}

The results show significant positive correlations between personal factors, age, comorbidity, and social support toward burden scores and quality of care. The social support was the most dominant factor for the quality of care from QUALCARE scales; each emotional and instrumental support correlated with features quality of care medical, psychology, and economic dimension; each appraisal support is associated with components quality of care environment, medical, psychology, human right, and economic dimension; each information support is associated with details quality of care medical dimension. The caregiver's context is essential. It found that emotional and social support were related to the quality of care in the medical and psychological factors. Resource social support was associated with the quality of care in the medical, psychological, and financial aspects. Social support for self-acceptance and selfworth is related to the quality of environmental care. The subsequent research is to determine health-care providers' role and long-term care systems education. Also, proactive health services from a multidisciplinary team make it possible to access services from home in helping to supervise and monitor ongoing care.

\section{Acknowledgments}

The authors would like to thank the participants' involvement in this research and grant supporting research funding in the nursing production project, Ramathibodi School of Nursing, Faculty of Medicine Ramathibodi Hospital, Mahidol University, Thailand. 


\section{Disclosure}

The authors report no conflicts of interest for this work.

\section{References}

1. World Health Organization. Integrated Care for Older People: Guidelines on Community-Level Interventions to Manage Declines in Intrinsic Capacity. Geneva; 2017.

2. O'Shea E. Improving the Quality of Life of Elderly Persons in Situations of Dependency. Strasbourg Cedex, France: Council of Europe Publishing; 2002.

3. Komazawa O, Saito Y. Coping with Rapid Population Ageing in Asia Discussions on Long-Term Care Policy and Cross-Border Circulation of Care Workers. Jakarta: Economic research institute for ASEAN and East Asia (ERIA); 2021.

4. Malee S. Office of the civil service commission: HR update known the aging society and the situation of the older people (In Thailand) OCSC E-J. 2018;60(4):5-8.

5. Department of Provincial Administration, Ministry of Interior. Older statistics in Thailand 77 as of December 31, 2019. Available from: http:/ www.dop.go.th/th/know/side/1/1/275. Accessed December 30, 2020.

6. Suanrueang P, Wannasri A, Srithamrongsawat S. Community care by caregivers to dependent elderly under the community-based long-term care policy. J Health Serv Res Policy. 2018;12(3):437-451.

7. Vajragupta Y, Kunakornvong W, Phatchana P, Suriyanratakorn S. An effectiveness analysis of the long-term care plans in Udon Thani Province. J Health Sci Res. 2018;12(4):608-624.

8. Ratanavilaisakul R. Quality of life and happiness of people in community, ThungKhru district, Bangkok. The 4th national conference on public affairs management, public affairs management under Thailand 4.0; 2018. Available from: https://conference.kku.ac.th/ colaimg/files/articles/ad709-o-86-.pdf. Accessed September 9, 2021.

9. Anderson KH, Tomlinson PS. The family health system as an emerging paradigmatic view for nursing. Image J Nurs Sch. 1992;24 (1):57-63.

10. Donabedian A. The quality of care: how can it be assessed? JAMA. 1988;260(12):1743-1748. doi:10.1001/jama.1988.03410120089033

11. House JS. Work Stress and Social Support. Reading, MA: AddisonWesley; 1981.

12. Phillips LR, Morrison EF, Chae YM. The QUALCARE scale: developing an instrument to measure quality of home care. Int J Nurs Stud. 1990a;27(1):61-75. doi:10.1016/0020-7489(90)90024-D

13. Toonsiri C, Sunsern R, Lawang W. Development of the burden interview for caregivers of patients with chronic illness. J Nurs Educ. 2011;4(1):62-75.

14. Cohen J. Statistical Power Analysis for the Behavioral Sciences. 2nd ed. Hillsdale, NJ: Lawrence Erlbaum Associates, Publishers; 1988.

15. Zainuddin J, Arokiasamy JT, Poi PJH. Caregiving burden is associated with short rather than long duration of care for older persons. Asia Pacific Journal of Public Health. 2003;15(2):88-93. doi:10.1177/101053950301500203

Journal of Multidisciplinary Healthcare

\section{Publish your work in this journal}

The Journal of Multidisciplinary Healthcare is an international, peerreviewed open-access journal that aims to represent and publish research in healthcare areas delivered by practitioners of different disciplines. This includes studies and reviews conducted by multidisciplinary teams as well as research which evaluates the results or conduct of such teams or healthcare processes in general. The journal

Submit your manuscript here: https://www.dovepress.com/journal-of-inflammation-research-journal
16. Choo W, Low W, Karina R, Ebenexer E, Prince MJ. Social support and burden among caregivers of patients with dementia in Malaysia. Asia Pac J Public Health. 2003;15(1):23-29. doi:10.1177/1010539 50301500105

17. Chou Y, Lee Y, Lin L, Kro"ger T, Chang A. Older and younger family caregivers of adults with intellectual disability: factors associated with future plans. Intellect Dev Disabil. 2009;47(4):282-294. doi:10.1352/1934-9556-47.4.282

18. Kajonius PJ, Kazemi A. Structure and process quality as predictors of satisfaction with elderly care. Health Soc Care Community. 2016;24 (6):699-707. doi:10.1111/hsc. 12230

19. Beach SR, Schulz R. Family caregiver factors associated with unmet needs for care of older adults. J Am Geriatr Soc. 2016;65(3):560-566.

20. Werdhani RA, Sulistomo AW, Herqutanto WI, Rahajeng E, Stomo AH, Mansyur M. Correlation of leadership and care coordinator performance among primary care physicians. J Multidiscip Healthc. 2018;11:691-698. doi:10.2147/JMDH.S174917

21. Blair A, Bateman C. "They take a lot of pressure off us": volunteers reducing staff and family care burden and contributing to quality of care for older patients with cognitive impairment in rural hospitals. Australas J Ageing. 2019;38(Suppl. 2):34-45. doi:10.1111/ajag.12612

22. Aman Z, Liew SM, Ramdzan SN MBBS, Philp I, Khoo EM. The impact of caregiving on caregivers of older persons and its associated factors: a cross-sectional study. Singapore Med J. 2020;61 (5):238-245. doi:10.11622/smedj.2019100

23. Koopman E, Heemskerk M, Beek AL, Coenen P. Factors associated with caregiver burden among adult (19-64 years) informal caregivers an analysis from Dutch municipal health service data. Health Soc Care Community. 2020;28:1578-1589. doi:10.1111/hsc.12982

24. Hanh PT, Jullamate P, Piphatvanitcha N. Factors related to caregiver burden among family caregivers of older adults with stroke in Hai Duong, Vietnam. South Coll Network J Nurs Public Health. 2018;4 (3):45-62.

25. World Health Organization. Handbook for National Quality Policy and Strategy: A Practical Approach for Developing Policy and Strategy to Improve Quality of Care. Geneva, Switzerland; 2018.

26. Yeh P, Chang Y. Use of zarit burden interview in analysis of family caregivers' perception among Taiwanese caring with hospitalized relatives. Int J Nurs Pract. 2014;21(5):622-634. doi:10.1111/ijn.12333

27. Limpawattana $P$, Intarasattakul $N$, Chindaprasirt J, Tiamkao S. Perceived burden of Thai caregivers for older adults after stroke. Clin Gerontol. 2015;38(1):19-31. doi:10.1080/07317115.2014.970315

28. Lilleheie I, Debesay J, Bye A, Bergland A. Informal caregivers' views on the quality of healthcare services provided to older patients aged 80 or more in the hospital and 30 days after discharge. $B M C$ Geriatr. 2020;20(97):1-13. doi:10.1186/s12877-020-1488-1

29. Plothner M, Schmidt K, de Jong L, Zeidler J, Damm K. Needs and preferences of informal caregivers regarding outpatient care for the elderly: a systematic literature review. BMC Geriatr. 2019;19(1):82. doi:10.1186/s12877-019-1068-4 covers a very wide range of areas and welcomes submissions from practitioners at all levels, from all over the world. The manuscript management system is completely online and includes a very quick and fair peer-review system. Visit http://www.dovepress.com/testimonials. php to read real quotes from published authors. 